\title{
Introduction: Conceptualizing in a second language
}

\author{
CHRISTIANE VON STUTTERHEIM, MONIQUE FLECKEN \\ AND MARY CARROLL
}

Research on second language (L2) ${ }^{1}$ acquisition has gone through a number of phases leading to an accumulation of insights into processes that are increasingly complex in nature. In short, this development can be characterised as starting with form, moving into functions and then into processes, thereby mirroring changes in perspective in linguistics in general. Language learning was initially viewed in behaviorist terms whereby learners would gradually learn the correct forms through habit formation and reinforcement. This view on second language learning changed with the advent of the concept of an interlanguage (Selinker 1972), based on theories of language as complex systems structured on different levels (phonology, syntax, semantics), and the study of contact varieties (pidgins, creoles) as linguistic systems in their own right (cf. Klein and Dittmar 1979). In this phase studies focussed on the acquisition of forms identifying learner-specific acquisitional sequences in certain structural domains, such as verbal and nominal morphology, pronoun systems, word order, etc. (cf. Klein 1988; Cook 1992). Factors considered in explaining the empirical findings were structural properties of the native language (L1), the target language (L2), contrasts between the languages involved, as well as the role of explicit learning versus implicit acquisition, socio-cultural factors and age of learning onset. This mainly form-oriented approach, however, could not answer questions concerning the high degree of variation, both between as well as within subjects, nor could it address questions related to the driving forces behind acquisitional steps. This led to a shift from a focus on form to a focus on function, taking semantic categories as the starting point of the analyses - phase II in L2 acquisition research (Klein and Perdue 1993; overviews in

1. The terms L2 speaker, L2 user, learner or bilingual will be used interchangably throughout this issue. All terms are neutral with respect to speaker-specific characteristics, such as proficiency, age of acquisition, etc. All empirical studies will define the samples investigated in those terms, specifically. 
Ritchie and Bhatia 1996; Robinson 2013). Studies on the acquisition of expressive devices for spatial or temporal categories are representative of this phase, based on the perspective of the learner who has the task of acquiring new devices for the expression of existing conceptual content and communicative practice (Andersen and Shirai 1994; Dietrich et al. 1995). This perspective allowed for an integrated analysis of components of learner languages across different structural areas. At the same time it provided a framework for the inclusion of more general cognitive processes (such as limitations on processing capacity, the necessity of solving competition between means as the system develops, time constraints; cf. surveys in Ellis 1994). This approach prepared the ground for phase III which is characterized by a shift from product to process. Language acquisition is viewed as a multifactorial cognitive process which can only be understood on the basis of a differentiated picture of the types of knowledge involved, as well as the procedures which lead to the storage and use of L2 material. In this context, analytic methods in psycholinguistics have been applied and combined with qualitative linguistic methods, providing the basis for insights into mental processes underlying L2 use. Domains of research were first located at the micro-structural level, looking into lexical storage and retrieval, as well as structural areas. With further elaboration in methodology, research objectives were extended to address complex questions concerning information organization at the micro- and macro-structural level in the L2 (e.g., Doughty and Long 2005). Within this framework a line of research was established in which second language acquisition was related to cognitive typology (see, for example, Lucy 1992). The questions in focus under this perspective can be formulated as follows:

- Are there language-specific patterns of conceptualization, for example, of events or situations which vary in correlation with typological differences?

- How are language-specific patterns acquired in the process of L2 acquisition, where the speakers' conceptualization of content in language processing is based, not on single form-function relations, but on clusters of formfunction relations which are language-specific (e.g., Achard and Niemeier 2004; Han and Cadierno 2010; Cook and Bassetti 2011; Pavlenko 2011; Benazzo, Flecken and Soroli 2012)?

Slobin's hypothesis on thinking for speaking has been a fruitful theoretical framework for L2 acquisition research (Slobin 1996), and it is in this context that this special issue is situated. The present studies address the question of how language-specific knowledge is acquired in a second language. The type of knowledge investigated encompasses principles of information organization, both within and across sentences, which form the basis for language production and comprehension in all its facets. These principles are rooted at a conceptual level, that is to say, they result from the interplay of languagespecific semantic and syntactic constraints in different domains such as time, 
space, entities. In this sense, the studies go beyond the acquisition of linguistic structure as such. The focus is placed, rather, on language-specific preferences in the way in which entire situations, events or event sequences in the world around us, and the associated ontological domains (time, space, entities) are conceptually organized and integrated given a verbal task. The study of information organization in the present framework thus relates to linguistic knowledge at the so-called 'interface' between grammar, semantics, and pragmatics (see definitions in Kamp and Reyle 1993; van Valin and La Polla 1997). In this context, special focus is placed on the role of grammaticalized concepts, i.e., the way concepts relating to the domains of time, entities, space are grammaticalized, as well as lexicalized (verbal, nominal), and their relevance for information organization.

It has been shown that preferences in information organization at this level are not culturally determined habitual ways of attending to and referring to events and situations, but can be traced to differences in the way languages encode meaning on the basis of grammaticalized as well as lexicalized concepts. With the prominence accorded to specific concepts via specific forms of grammaticalization or lexicalization, language can function as an attentiondirecting mechanism to those aspects of a situation that are readily encodable by a specific language, when performing the act of speaking ("thinking for speaking" Slobin 1996). Research findings show that these "thinking for speaking" patterns develop relatively early during the acquisition of one's first language (Bowerman and Choi 2003; Allen et al. 2007; Ji et al. 2011). However, full mastery of principles of information organization at the level of complex texts lasts until the age of 13, 14 (von Stutterheim et al. 2011). Native speakers of a given language thus become habituated to attending to and representing situations or events in a particular way, due to extensive exposure and use of their L1.

A large number of previous studies have shown how grammaticalized structures that are relevant for event or narrative construal operate not only locally, but also globally, at the level of macro-structural planning for the task in question. For example, whether a language encodes progressive aspect morphologically on the verb or not, has implications for the way in which individual events are sequenced and linked in a narrative. Studies of different L1s show how grammatically-driven principles work in unison in information selection and information packaging, when producing a narrative text and how they vary cross-linguistically (von Stutterheim et al. 2003; Carroll et al. 2008). Second language learners have to uncover over-arching principles of this kind with regard to their consequences for information organization, and studies on L2 narratives show how those of advanced learners differ from L1 narratives across a range of areas (sequencing principles - ordering events, reference management, factors driving downgrading/subordination, etc., see Carroll and Lambert 2003; 
Dimroth and Starren 2003; von Stutterheim and Lambert 2005; Bylund 2011; Flecken 2011; Benazzo et al. 2012). The learners studied had extensive exposure to the target language through day to day contacts and communicative interaction, indicating that acquisition of the knowledge underlying information organization, as required in complex language production tasks, poses what is probably one of the main challenges for the language learner.

Looking now at the conceptualization of single events, cross-linguistic studies have traced language differences related to specific linguistic structures. For example, it was shown how the presence or absence of grammatical aspect influences attention distribution (as measured by means of eye tracking) to specific aspects of an event scene and information selection. In a study on motion events, use of progressive or imperfective aspect (English, Russian) leads to a segmentation of the event into phases, with a focus of attention on a specific phase of the event, namely the currently ongoing phase. Speakers of languages without aspect take a different perspective on the event - in this case a holistic perspective, with inclusion of a potential endpoint (von Stutterheim and Nüse 2003; Bylund 2009; Schmiedtová et al. 2011; von Stutterheim et al. 2012). A large number of studies on motion events have investigated the relevance of typological contrasts at the level of lexicalization which concern path and manner of motion, how they are expressed (verb stems versus verb satellites, Talmy 1985; Slobin 1996, 2006) and their role in L1 and L2 acquisition. Studies of L2 acquisition show that patterns in acquisition are more varied than predicted by simple interpretations of this typological contrast (see Slobin 2006; Brown and Gullberg 2008, 2011; Hendriks and Hickmann 2011; Slobin et al. 2011; Iakovleva 2012). A further area of interest with regard to single events concerns specificity and its expression in the context of causative events. Studies on the role of progressive aspect show how aspect and the marking of specificity is interrelated; use of the progressive in an event description in English will serve to encode the event as a specific case, since this aspectual distinction anchors the event as ongoing at the time of speech. In the absence of explicit verbal markers of progressive aspect, as in German, speakers encode specificity by relating to distinguishing features of the entities involved in the event. This contrasts with English, where event representation can be more abstract given the same task (Carroll and von Stutterheim 2011). Cross-linguistic differences in levels of specificity across different semantic categories and their role in L1 acquisition have been investigated in detail in Slobin et al. (2011).

As mentioned above, a range of studies on different types of L2 users and bilinguals have documented (besides the obvious cases of pronunciation/ phonology/morphology) how target language-specific patterns of information organization are difficult to acquire. Even for very advanced L2 users and simultaneous bilinguals who produce grammatically correct speech and do not report any problems with comprehension, the identification and use of target 
language principles underlying information organization and macro-planning has proved to be difficult. This is evidenced by findings showing transfer of first language patterns of information organization and conceptualization with respect to the role of prominent conceptual domains (conceptual or conceptualization transfer), as well as L2-specific principles based on restructuring of L1 language patterns (see definitions and comprehensive framework in Odlin 2005; Pavlenko 2005, 2011; Jarvis and Pavlenko 2008). These processes determine the structure of the L2, along with other learner-specific principles given with the course of development required in establishing the L2 as a viable linguistic system per se. On the whole, general principles of complexity reduction could be observed as typical of earlier stages of acquisition and performance.

In order to adequately compare patterns in both the L1 and the L 2 of speakers, and to provide a more complete picture of thinking for speaking patterns, it is essential to understand how L1 speakers proceed in organizing content for expression. The present state of the art confirms how indepth analyses of information organization in the learner's first language, that is, the way a system is used in specific complex tasks, can fruitfully serve as a baseline for the investigation of L2 acquisition. Fine-grained analyses of patterns in native speaker language production and comprehension provide a more differentiated basis for comparisons with L2 users, thereby allowing the identification of factors that affect the achievement of full proficiency at very advanced stages.

The present studies are in line with this current trend in that they present a large empirical basis covering language production and comprehension by native speakers of the following languages (English, German, Dutch, Japanese, Czech, French, Italian). The analyses serve as the point of reference on which L2 patterns are subsequently compared. The L2 users represent a large range of language combinations (Germanic-Germanic, Slavic-Germanic, GermanicJapanese, Romance-Romance), and a varied sample of L2 levels of proficiency (intermediate, advanced, very advanced and simultaneous (or early) bilingual speakers). The phenomena under investigation all include highly complex aspects of information organization, namely, information selection in motion event construal, aspectual perspective taking in event construal, patterns of linkage in narratives, pronoun resolution and reference management in specific discourse types. The papers address the following question: To what extent do L2 users manage to acquire language-specific principles underlying information organization that operate at sentence or discourse level in production and comprehension, as governed by specific grammaticalised or lexical structures, which may or may not overlap with the learners' source language?

The first paper by Schmiedtová investigates event construal by advanced Czech L2 speakers of English. Data from the current study are compared with a sample of advanced Czech L2 speakers of German, thus allowing an investigation of the role of the specific source-target language pair on performance. 
Findings are presented for two different event types and show how the influence of L1-specific patterns of conceptualization (conceptual transfer) prevail, besides the existence of learner-specific patterns.

The second paper on narratives by Tomita traces principles governing the use of additive and contrastive linkage by L1 speakers of German and Japanese when relating events, compared to a sample of advanced German L2 users of Japanese. The study identifies interesting language-specific strategies relating to the use of focus particles and the relevance of specific domains (entity versus time) in their scope properties at the macro-structural level. Learners' productions show a complex picture: the author finds evidence for a potential simplification strategy, but also traces of conceptual transfer of an L1-based focus.

Narrative performance by early as well as late French-Italian bilinguals is at the focus of the study by Natale. It starts with a detailed description of (monolingual) L1 speaker performance on the same task, identifying different patterns in subordination as well as coordination which are traced to a core typological difference between French and Italian: Italian is a null-subject language while French is not. The late bilinguals are at an intermediate level and show traces of conceptual transfer from French, as well as predominant use of learner-specific principles in both coordinating and subordinating utterances. Although the early bilinguals display a pattern which is closer to the target language, and make use of the range of means at issue, they have not yet acquired the hierarchical ranking displayed for different forms of subordination in a language with null subject, and their role in ensuring topic maintenance and information flow, as observed in L1 Italian.

Ellert provides a visual world eye tracking study which looks at the comprehension of ambiguous pronouns in German by advanced Dutch learners of German (personal pronouns and d-pronouns). Native German resolution patterns are determined by syntax-pragmatic factors, a pattern which is similar to the one found in Dutch. Nevertheless, the Dutch learners of German do not display a target-like pattern. Their performance can thus be interpreted as learner-specific.

Lastly, van Beek, Flecken and Starren investigate patterns in aspectual perspective taking by a sample of very advanced German learners of Dutch. L1 Dutch is an interesting point of reference in the study of acquisition in this domain, as the use of aspect is determined by specific situation types. Findings for the L2 German learners of Dutch (a source language that does not encode progressive aspect) are discussed in comparison to a sample of early German-Dutch bilinguals, as well as a sample of advanced English learners of Dutch (a source language with fully grammaticalized progressive aspect). Focus is placed on potential differences with regard to conceptual transfer effects determined by the $\mathrm{L} 1$. 
In the final chapter, we discuss the empirical papers in terms of patterns of conceptual transfer or restructuring in the bilingual mind, and highlight a set of important factors that were found to play a role for the patterns obtained, indicating important objectives for future research on the L2 acquisition of complex conceptual knowledge.

Heidelberg University

〈stutterheim@idf.uni-heidelberg.de〉

Radboud University Nijmegen

$\langle$ m.flecken@donders.ru.nl

Heidelberg University

〈carroll@idf.uni-heidelberg.de〉

\section{References}

Achard, Michel \& Susanne Niemeier (eds.). 2004. Cognitive linguistics, second language acquisition, and foreign language teaching. Berlin: Mouton de Gruyter.

Allen, Shanley, Asli Özyürek, Sotaro Kita, Amanda Brown, Reyhan Furman, Tomoko Ishizuka \& Mihoko Fujii. 2007. Language-specific and universal influences in children's syntactic packaging of manner and path: A comparison of English, Japanese, and Turkish. Cognition 102(1). $16-48$.

Andersen, Roger W. \& Yasuhiro Shirai. 1994. Discourse motivations for some cognitive acquisition principles. Studies in second language acquisition 16(2). 133-156.

Benazzo, Sandra, Cecilia Andorno, Grazia Interlandi \& Cedric Patin. 2012. Perspective discursive et influence translinguistique: Exprimer le contraste d'entité en français et en italien L2. Language, interaction and acquisition (LIA) 3(2). 173-201.

Benazzo, Sandra, Monique Flecken \& Efstathia Soroli. 2012. Typological perspectives on language and thought: Thinking for speaking in L2. [Special issue]. Language, interaction and acquisition (LIA) 3(2).

Bowerman, Melissa \& Soonja Choi. 2003. Space under construction: Language specific spatial categorization in first language acquisition. In Dedre Gentner \& Susan Goldin-Meadow (eds.), Language in mind: Advances in the study of language and cognition, 387-428. Cambridge: MIT Press.

Brown, Amanda \& Marianne Gullberg. 2008. Bidirectional crosslinguistic influence in L1-L2 encoding of manner in speech and gesture: A study of Japanese speakers of English. Studies in second language acquisition 30(2). 225-251.

Brown, Amanda \& Marianne Gullberg. 2011. Bidirectional cross-linguistic influence in event conceptualization: Expressions of path among Japanese learners of English. Bilingualism: Language and cognition 14 (1). 79-94.

Bylund, Emanuel. 2009. Effects of age of L2 acquisition on L1 event conceptualization patterns. Bilingualism: Language and cognition 12 (3). 305-322.

Bylund, Emanuel. 2011. Segmentation and temporal structuring of events in early SpanishSwedish bilinguals. International journal of bilingualism 15. 86-54.

Carroll, Mary \& Monique Lambert. 2003. Information structure in narratives and the role of grammaticised knowledge: A study of adult French and German learners of English. In Christine Dimroth \& Marianne Starren (eds.), Information structure and the dynamics of language acquistion, 267-287. Amsterdam: Benjamins. 


\section{Christiane von Stutterheim, Monique Flecken and Mary Carroll}

Carroll, Mary, Antje Rossdeutscher, Monique Lambert \& Christiane von Stutterheim. 2008. Subordination in narratives and macro-structural planning: A comparative point of view. In: Cathrine Fabricius Hansen \& Wiebke Ramm (eds.), 'Subordination' versus 'coordination' in sentence and text, 161-184. Amsterdam: Benjamins.

Carroll, Mary \& Christiane von Stutterheim. 2011. Event representation, time event relations, and clause structure: A crosslinguistic study of English and German. In Jürgen Bohnemeyer \& Eric Pederson (eds.), Event representation in language and cognition, 68-82. Cambridge: Cambridge University Press.

Cook, Vivian J. 1992. Evidence for multicompetence. Language learning 42(4). 557-591.

Cook, Vivian J. \& Benedetta Bassetti (eds.). 2011. Language and bilingual cognition. Hove, UK: Psychology Press.

Dietrich, Rainer, Wolfgang Klein \& Colette Noyau. 1995. The acquisition of temporality in a second language. Amsterdam: Benjamins.

Dimroth, Christine \& Marianne Starren (eds.). 2003. Information structure and the dynamics of language acquisition. Amsterdam: Benjamins.

Doughty, Catherine J. \& Michael H. Long (eds.). 2005. The handbook of second language acquisition. London: Blackwell.

Ellis, Rod. 1994. The study of second language acquisition. Oxford: Oxford University Press.

Flecken, Monique. 2011. Macro-planning in narratives: Assessing bilingual attainment. International journal of bilingualism 15(2). 164-186.

Han, ZhaoHong \& Teresa Cadierno (eds.). 2010. Linguistic relativity in SLA: Thinking for speaking. Clevedon: Multilingual Matters.

Hendriks, Henriëtte \& Maya Hickmann. 2011. Space in second language acquisition. In Vivian Cook \& Benedetta Bassetti (eds.), Language and bilingual cognition, 315-339. Hove: Psychology Press.

Iakovleva, Tatiana. 2012. Typological constraints in foreign language acquisition: The expression of voluntary motion by upper intermediate and advanced Russian learners of English. Language, interaction and acquisition (LIA) 3(2). 231-260.

Jarvis, Scott \& Aneta Pavlenko. 2008. Crosslinguistic influences in language and cognition. London: Routledge.

Ji, Yinglin, Henriëtte Hendriks \& Maya Hickmann. 2011. Children's expression of voluntary motion events in English and Chinese. Journal of foreign languages 34(4). 2-20.

Kamp, Hans \& Uwe Reyle. 1993. From discourse to logic. Dordrecht: Kluwer.

Klein, Wolfgang \& Norbert Dittmar. 1979. Developing grammars. Berlin: Springer.

Klein, Wolfgang. 1988. Second language acquisition. Cambridge: Cambridge University Press.

Klein, Wolfgang \& Clive Perdue. 1992. Utterance structure: Developing grammars again. Amsterdam: Benjamins.

Lucy, John A. 1992. Grammatical categories and cognition: A case study of the linguistic relativity hypothesis. Cambridge: Cambridge University Press.

Odlin, Terence. 2005. Crosslinguistic influence and conceptual transfer: what are the concepts? Annual review of applied linguistics 25. 3-25.

Pavlenko, Aneta. 2005. Emotions and multilingualism. Cambridge: Cambridge University Press.

Pavlenko, Aneta (ed.). 2011. Thinking and speaking in two languages. Clevedon: Multilingual Matters.

Ritchie, William C. \& Tej K. Bhatia (eds.). 1996. Handbook of second language acquisition (vol. 2). San Diego: Academic Press.

Robinson, Peter (ed.). 2013. The Routledge encyclopedia of second language acquisition. New York: Taylor and Francis.

Schmiedtová, Barbara, Christiane von Stutterheim \& Mary Carroll. 2011. Language-specific patterns in event construal of advanced second language speakers. In Aneta Pavlenko (ed.), Thinking and speaking in two languages, 66-107. Clevedon: Multilingual Matters.

Selinker, Larry. 1972. Interlanguage. IRAL 10(3). 209-231. 
Slobin, Dan I. 1996. From "Thought and language" to "Thinking for speaking". In John Gumperz \& Stephen Levinson (eds.), Rethinking linguistic relativity, 70-96. Cambridge: Cambridge University Press.

Slobin, Dan I. 2006. What makes manner of motion salient?: Explorations of linguistic typology, discourse, and cognition. In Maya Hickmann and Stéphane Robert (eds.), Space in languages: Linguistic systems and cognitive categories, 59-81. Amsterdam: Benjamins.

Slobin, Dan I., Melissa Bowerman, Penelope Brown, Sonja Eisenbeiss \& Bhuvana Narasimhan. 2011. Putting things in places: Developmental consequences of linguistic typology. In Jürgen Bohnemeyer \& Eric Pederson (eds.), Event representation in language and cognition, 134-165. Cambridge: Cambridge University Press.

Stutterheim, Christiane von, Mary Carroll \& Wolfgang Klein. 2003. Two ways of construing complex temporal structures. In Friedrich Lenz (ed.), Deictic conceptualization of space, time and person, 97-133. Berlin: de Gruyter.

Stutterheim, Christiane von \& Ralf Nüse. 2003. Processes of conceptualization in language production: Language-specific perspectives and event construal. Linguistics 41(5). 831-881.

Stutterheim, Christiane von \& Monique Lambert. 2005. Crosslinguistic analysis of temporal perspectives in text production. In Henriëtte Hendriks (ed.), The structure of learner varieties, 203-230. Berlin: Mouton de Gruyter.

Stutterheim, Christiane von, Ute Halm \& Mary Carroll. 2011. Macro-structural principles and the development of narrative competence in L1 German: The role of grammar (8-14 year olds). In Sandra Benazzo, Maya Hickmann \& Marzena Watorek (eds.), Comparative perspectives to language acquisition: A tribute to Clive Perdue, 559-585. Clevedon: Multilingual Matters.

Stutterheim, Christiane von, Martin Andermann, Mary Carroll, Monique Flecken \& Barbara Schmiedtová. 2012. How grammaticized concepts shape event conceptualization in language production: Insights from linguistic analysis, eye tracking data and memory performance. Linguistics 50(2). 833-867.

Talmy, Leonard. 1985. Lexicalization patterns: Semantic structure in lexical forms. In Timothy Shopen (ed.), Language Typology and Syntactic Description, Vol.3: Grammatical Categories and the Lexicon, 57-149. Cambridge: Cambridge University Press.

Valin Jr., Robert D. van \& Randy J. La Polla. 1997. Syntax: Structure, Meaning, and Function (Cambridge Textbooks in Linguistics Series). Cambridge: Cambridge University Press. 